\title{
Is D2 laparoscopic gastrectomy essential for elderly patients with advanced gastric cancer? A propensity score matched analysis
}

\author{
Masazumi Sakaguchi^, Hisahiro Hosogi, Seiichiro Kanaya \\ Department of Surgery, Japanese Red Cross Osaka Hospital, Osaka, Japan \\ Contributions: (I) Conception and design: M Sakaguchi; (II) Administrative support: None; (III) Provision of study materials or patients: None; (IV) \\ Collection and assembly of data: M Sakaguchi; (V) Data analysis and interpretation: M Sakaguchi, H Hosogi; (VI) Manuscript writing: All authors; \\ (VII) Final approval of manuscript: All authors. \\ Correspondence to: Masazumi Sakaguchi. Department of Surgery, Japanese Red Cross Osaka Hospital, 5-30 Fudegasakicho, Tennoji Ward, Osaka, 543- \\ 8555, Osaka, Japan. Email: maskgch@kuhp.kyoto-u.ac.jp.
}

\begin{abstract}
Background: The necessity of the standard D2 gastrectomy for elderly patients with advanced gastric cancer (GC) is controversial because only limited data are available to demonstrate its oncological benefit for them. Our aim was to compare the outcomes of D2 and Non-D2 and to evaluate the survival benefit of D2 laparoscopic gastrectomy (LG) in elderly patients.
\end{abstract}

Methods: We retrospectively identified 865 patients with GC who underwent radical LG at our hospital between 2011 and 2017. Patients aged $\geq 75$ years who were diagnosed with clinical T1N+ or clinical T2-4 were eligible. The primary outcome was the 3 -year overall survival (OS) rate. The confounding factors were minimized using propensity score matching.

Results: This study included 119 patients (63 D2 LG and 56 Non-D2 LG), and 52 patients (26 each for D2 LG and Non-D2 LG) were analyzed after matching. Although no significant difference was found in overall major complications $(\mathrm{P}=1.00)$, complications tended to occur in the $\mathrm{D} 2$ group (D2 vs. Non-D2 =3.9\% vs. $0 \%)$. No differences in the 3 -year OS were noted between the two groups $(68.8 \%$ vs. $68.8 \%$; HR 1.53 , 95\% CI: 0.56-3.19).

Conclusions: This study demonstrated the possible association between D2 LG and increased complication rate and no survival benefit of D2 LG in elderly patients.

Keywords: Elderly patients; advanced gastric cancer; laparoscopic gastrectomy; D2 lymphadenectomy

Submitted Sep 29, 2021. Accepted for publication Dec 14, 2021.

doi: 10.21037/jgo-21-640

View this article at: https://dx.doi.org/10.21037/jgo-21-640

\section{Introduction}

According to the GLOBOCAN database, gastric cancer (GC) is the fifth most common cancer and the third leading cause of cancer-related deaths worldwide (1). Notably, the incidence of GC increases steeply with age in Japan as well as worldwide $(2,3)$. Although gastrectomy with D2 lymphadenectomy (D2 gastrectomy) is a standard procedure for GC, some reports showed that elderly patients with
GC had a higher risk of postoperative death than younger patients when the patients were divided into subgroups according to the different age ranges (4-6).

Some reports have analyzed the long-term outcomes of open gastrectomy (OG) in elderly patients with GC. A retrospective propensity score-matching analysis (PSM) showed that gastrectomy had a positive impact on the OS in elderly patients compared to the best supportive care (7). Another PSM analysis of a multi-institutional dataset

\footnotetext{
$\wedge$ ORCID: 0000-0002-3885-2503.
} 
showed that D2 open gastrectomy (D2 OG) conferred little oncological benefit despite increased mobility for elderly patients with GC (8). Therefore, gastrectomy is an essential treatment even for elderly patients with GC; however, D2 OG cannot be recommended as a standard treatment.

Recently, laparoscopic gastrectomy (LG), also known as minimally invasive surgery, has been widely used for GC, because it has better short-term postoperative outcomes and maintains oncological safety compared to OG (9-17). However, it should be noted that the subjects in those studies were relatively young and healthy patients. Lesser invasiveness and oncological safety of LG can be the same as that for elderly patients with GC. Therefore, considering that elderly patients are at a high risk of postoperative complications and death caused by other diseases in the long-term follow-up, it remains unclear whether D2 laparoscopic gastrectomy (D2 LG) confers survival benefits similar to D2 OG.

In this study, we aimed to evaluate whether D2 LG was beneficial for the elderly patients with GC, using a PSM analysis. We present the following article in accordance with the STROBE reporting checklist (available at https:// jgo.amegroups.com/article/view/10.21037/jgo-21-640/rc).

\section{Methods}

\section{Patients}

We retrospectively analyzed the cohort data of 865 consecutive patients with GC who underwent radical LG with lymphadenectomy at our hospital between 2011 and 2017. Patients who were older than 75 years were included, and their data were collected from the medical records. We excluded the patients with remnant gastric cancer, patients who underwent palliative surgery or R2 resection, patients who received neoadjuvant chemotherapy, patients with cT1N0 GC, and patients who underwent proximal gastrectomy. Lymphadenectomy was either D2 dissection (D2) or non-D2 dissection (Non-D2) based on the Japanese gastric cancer treatment guidelines (4). All operations were performed by experienced surgeons or trainee supervised by experienced surgeons. An experienced surgeon was defined as a qualified surgeon by the Endoscopic Surgical Skill Qualification System of the Japanese Society for Endoscopic Surgery. The clinical and pathological stages were recorded according to the 3rd English edition of the Japanese Gastric Cancer Classification (18).

\section{Data definitions}

The short-term outcomes assessed included morbidity based on the Clavien-Dindo classification. Complications of CD grade II or higher were considered as postoperative complications, and complications of CD grade III or higher were considered as major complications. Pancreatic fistula was diagnosed on the basis of the international study group for pancreatic fistula (19). An intra-abdominal abscess was diagnosed when a patient had a fever of $38{ }^{\circ} \mathrm{C}$ or higher and intraperitoneal fluid collection demonstrated by MD-CT. Anastomotic leakage was defined as a defect of the gastric or intestinal wall at the anastomotic site, diagnosed by contrast swallow and/or MD-CT. Pneumonia was diagnosed by respiratory symptoms, blood tests, and X-ray or MDCT. Oncological safety was assessed by the 3 -year overall survival (OS), relapse-free survival (RFS), cancer-specific survival (CSS), and pathological findings. Overall survival was defined as the time from the day of operation to death from any cause; RFS was defined as the time from the day of operation to the recurrent day or death from any cause; and CSS was defined as the time from the day of operation to death due to gastric cancer.

\section{Statistical analysis}

Continuous data were compared using the Mann-Whitney $U$ test. The categorical variables were compared using the chi-square test or Fisher's exact test. Statistical significance was set $\mathrm{P}<0.05$. The overall survival, RFS, and CSS were assessed by plotting Kaplan-Meier curves. Cox's proportional hazard model was used to estimate the hazard ratios (HRs) with 95\% confidence intervals (CIs).

Propensity score matching was conducted to reduce confounding effects. The propensity score is the probability that an individual patient would have been assigned to undergo D2 dissection, conditional on observed covariates. Propensity scores were estimated using a logistic regression model based on age, sex, body mass index, American Society of Anesthesiologists Physical Status (ASA-PS), clinical T, clinical $\mathrm{N}$, and procedures. D2 cases were matched 1:1 to Non-D2 cases with similar pre-interventional probability without a replacement using a 0.2 caliper width. Although there is no consensus on which thresholds for standardized differences should be used to detect the residual imbalance across groups in matched samples, an absolute standardized difference of more than 0.25 was considered as a sign of 


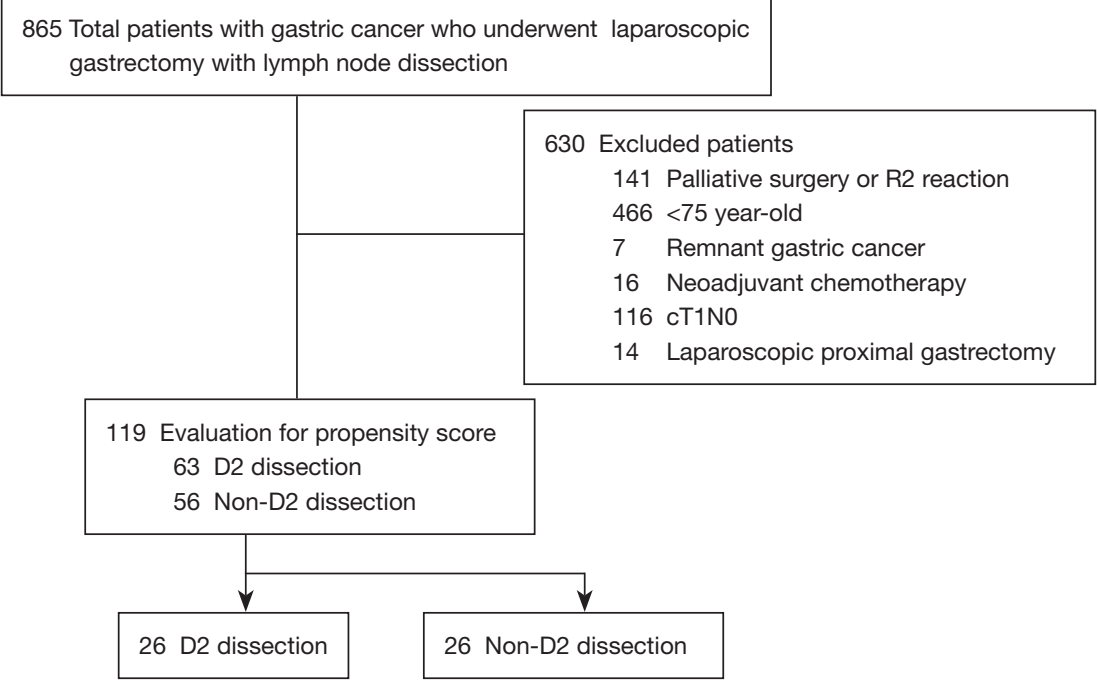

Figure 1 Study design.

imbalance according to the some reports (20-22). The resulting score-matched pairs were analyzed subsequently. All statistical analyses were performed using the JMP 14 software (SAS institute, Cary, NC, USA).

\section{Ethical statement}

This study was conducted in accordance with the Declaration of Helsinki (as revised in 2013). It was approved by the ethics committee of Japanese Red Cross Osaka Hospital (J-0238). The requirement to obtain individual patient consent was waived given the retrospective nature of study.

\section{Results}

\section{Patient characteristics}

We identified 119 consecutive eligible patients from the original cohort. Of these, 63 patients underwent D2 LG and 56 patients underwent Non-D2 LG. Propensity scores were estimated for each patient; additionally, the c-statistic was $83.3 \%$, indicating a high discrimination ability. After matching, 52 patients (26 each for D2 and Non-D2) were included in the analysis group (Figure 1).

Table 1 shows the patients' backgrounds before and after matching. In our cohort, the candidates for D2 were younger, and had better physical status, and more advanced clinical $\mathrm{N}$ than Non-D2 candidates. The rate of laparoscopic distal gastrectomy in the D2 group was higher than that in the Non-D2 group. After matching, all the variables were well balanced.

\section{Surgical and pathological findings}

Table 2 showed surgical outcomes and pathological findings. In the Non-D2 group, 24 and 2 patients underwent D1+ and D1 dissection, respectively. In the D2 group, 6 patients underwent D2+No.10 dissection. Of these, D2 laparoscopic total gastrectomy (LTG) with splenectomy was performed in 2 patients, and LTG with spleen-preserving D2 dissection was performed in 4 patients. In clinical practice, we only place a drain for the patients at high risk. The drain placement rate was also similar between the groups (50.0\% vs. $42.3 \%, \mathrm{P}=0.78)$. The overall major complication rates were $3.9 \%$ in the $\mathrm{D} 2$ group and $0 \%$ in the Non-D2 group $(\mathrm{P}=1.00)$. The $\mathrm{D} 2$ group had 1 pancreatic fistula, and 3 intra-abdominal abscesses, and 1 anastomotic leakage. In contrast, the Non-D2 group had no intra-abdominal infectious complications. Pneumonia was observed in 2 patients in each group. There are no significant difference in the retrieved lymph nodes and pathological findings between the D2 group and the Non-D2 group.

\section{Postoperative outcomes}

The median follow-up periods were 1,288 and 1,062 days in the D2 and Non-D2 groups, respectively. During the follow-up period, 8 patients and 5 patients experienced 
Table 1 Variable used for propensity score calculation

\begin{tabular}{|c|c|c|c|c|c|c|c|c|}
\hline Variables & \multicolumn{3}{|c|}{ Before matching $(n=119)$} & $\begin{array}{c}\text { Standardized } \\
\text { difference }^{\dagger}\end{array}$ & \multicolumn{3}{|c|}{ After matching $(n=52)$} & $\begin{array}{l}\text { Standardized } \\
\text { difference }\end{array}$ \\
\hline $\begin{array}{l}\text { Age, years, median } \\
\text { (range) }\end{array}$ & 78 (75-86) & $81(75-89)$ & 0.0010 & -0.66 & $80(75-86)$ & $81(75-89)$ & 0.8830 & -0.07 \\
\hline Sex, n (\%) & & & 0.8391 & & & & 0.7554 & \\
\hline Male & $44(69.8)$ & $41(73.2)$ & & -0.07 & $18(69.2)$ & $20(76.9)$ & & -0.17 \\
\hline BMI, median (range) & $\begin{array}{c}21.9 \\
(14.8-28.3)\end{array}$ & $\begin{array}{c}22.1 \\
(17.0-30.9)\end{array}$ & 0.0306 & -0.26 & $\begin{array}{c}22.1 \\
(17.4-27.1)\end{array}$ & $\begin{array}{c}21.5 \\
(17.0-25.1)\end{array}$ & 0.4924 & 0.23 \\
\hline ASA-PS, n (\%) & & & 0.0484 & & & & 0.7265 & \\
\hline $1 / 2$ & $57(90.5)$ & $43(76.8)$ & & 0.38 & $22(84.6)$ & $20(76.9)$ & & 0.20 \\
\hline $\mathrm{T} 1 \mathrm{~b}$ & $1(1.6)$ & $0(0)$ & & 0.18 & $0(0)$ & $0(0)$ & & \\
\hline T2 & $24(38.1)$ & $22(39.3)$ & & -0.02 & $11(42.3)$ & $9(34.6)$ & & 0.16 \\
\hline T3 & $25(39.7)$ & $20(35.7)$ & & 0.08 & $10(38.5)$ & $10(38.5)$ & & 0.00 \\
\hline T4 & $13(20.6)$ & $14(25.0)$ & & -0.10 & $5(19.2)$ & 7 (26.9) & & -0.18 \\
\hline Clinical N stage, n (\%) & & & 0.0370 & & & & 1.0000 & \\
\hline No & $34(54.0)$ & 41 (73.2) & & -0.41 & 20 (76.9) & $21(80.8)$ & & -0.09 \\
\hline $\mathrm{N} 1-3$ & $29(46.0)$ & $15(26.8)$ & & 0.41 & $6(23.1)$ & $5(19.2)$ & & 0.09 \\
\hline
\end{tabular}

${ }^{\dagger}$, standardized difference is defined as the difference in means, scaled by the square root of the average of the two within-group variances: $d=\left(\overline{x_{1}}-\overline{x_{2}}\right) / \sqrt{\left(s_{1}^{2}+s_{2}^{2}\right) / 2}$ where $\overline{x_{1}}, \overline{x_{2}}$ are group means, and $s_{1}^{2}, s_{2}^{2}$ are group variances. ASA-PS, American Society of Anesthesiologist Physical Status; BMI, body mass index; LDG, laparoscopic distal gastrectomy; LTG, laparoscopic total gastrectomy.

recurrence in the D2 and Non-D2 groups, respectively $(\mathrm{P}=0.76)$. The patterns of the first recurrence site are shown in Table 3, and there was no significant difference in the patterns in both groups. The death rates in the D2 group were $50.0 \%$ and $34.6 \%$ in the Non-D2 group $(\mathrm{P}=0.40)$. Regarding the cause of death, gastric cancer related deaths were $19.2 \%$ and $7.7 \%$ in the D2 and Non-D2 groups, respectively $(\mathrm{P}=0.42)$. The 3 -year CSS was $83.8 \%(95 \%$ CI: $0.64-0.94)$ and $90.5 \%$ (95\% CI: $0.69-0.98)$ in the D2 and Non-D2 groups, respectively (Figure 2). The HR was 2.21 (95\% CI: $0.47-15.47, \mathrm{P}=0.35$ ). The 3 -year RFS was $59.6 \%$ (95\% CI: $0.40-0.77$ ) in the D2 group and $50.3 \%$ (95\% CI: $0.30-0.70)$ in the Non-D2 group, and HR was
0.99 (95\% CI: 0.44-2.27, P=0.99) (Figure 3). The 3-year OS was $68.8 \%$ (95\% CI: $0.49-0.84$ ) in the D2 group and $68.8 \%$ (95\% CI: $0.47-0.84$ ) in the Non-D2 group. HR was 1.53 (95\% CI: 0.56-3.19, $\mathrm{P}=0.53$ ) (Figure 4).

\section{Discussion}

This study investigated the postoperative outcomes and oncological benefits after LG with or without D2 dissection in elderly patients with GC, using a PSM analysis. The results showed that D2 LG did not contribute to the oncological benefit for the elderly patients with GC; however, it tended to increase the complication rates. 
Table 2 Surgical outcomes and pathological findings for matched sample of patients undergoing laparoscopic gastrectomy with D2 or Non-D2 dissection

\begin{tabular}{|c|c|c|c|}
\hline Variables & $\mathrm{D} 2(\mathrm{n}=26)$ & Non-D2 $(n=26)$ & $P$ value \\
\hline Estimated blood loss, g, median [range] & $2.5[0-250]$ & $0[0-300]$ & 0.3649 \\
\hline Drain placement, $\mathrm{n}(\%)$ & $13(50.0)$ & $11(42.3)$ & 0.7813 \\
\hline Time to oral intake, days, median [range] & 5 [3-21] & $5[3-18]$ & 0.9179 \\
\hline Major complications ( $\geq$ Clavien-Dindo Grade III), n (\%) & $1(3.9)$ & $0(0)$ & 1.0000 \\
\hline Pancreatic fistula ( $\geq$ Clavien-Dindo Grade II), n (\%) & $1(3.9)$ & $0(0)$ & 1.0000 \\
\hline Intra-abdominal abscess ( $\geq$ Clavien-Dindo Grade II), n (\%) & $3(11.5)$ & $0(0)$ & 0.2353 \\
\hline Anastomotic leakage ( $\geq$ Clavien-Dindo Grade II), n (\%) & $1(3.9)$ & $0(0)$ & 1.0000 \\
\hline Pathological T stage, $\mathrm{n}(\%)$ & & & 0.1893 \\
\hline $\mathrm{T} 1$ & $1(3.9)$ & $2(7.7)$ & \\
\hline $\mathrm{T} 2$ & $11(42.3)$ & $9(34.6)$ & \\
\hline T3 & $4(15.4)$ & $10(38.5)$ & \\
\hline $\mathrm{T} 4$ & $10(38.5)$ & $5(19.2)$ & \\
\hline Pathological N stage, n (\%) & & & 0.4710 \\
\hline No & $8(30.8)$ & $13(50.0)$ & \\
\hline N1 & $5(19.2)$ & $5(19.2)$ & \\
\hline III & $12(46.2)$ & $9(34.6)$ & \\
\hline IV & $2(7.7)$ & $2(7.7)$ & \\
\hline Residual tumor, n (\%) & & & 1.0000 \\
\hline Ro & $22(84.6)$ & $23(88.5)$ & \\
\hline $\mathrm{R} 1$ & $4(15.4)$ & $3(11.5)$ & \\
\hline
\end{tabular}

We targeted only the patients who oncologically needed the D2 dissection for accurate comparison; additionally, we used a PSM analysis to minimize the confounding factors. We considered a covariate balanced if the absolute standardized difference was less than 0.25 , although 0.25 was a rough cut-off compared to 0.10 of cut-off (20).
Therefore, even though the covariates' standardized difference was below 0.25 , they should be carefully evaluated, because they may yield a bias in the treatment effect estimate. In clinical practice, the clinical $\mathrm{N}$ stage and procedure are important factors by which the surgeons decide the extent to which the lymphadenectomy should 
Table 3 Postoperative outcomes for matched sample of patients undergoing laparoscopic gastrectomy with D2 or Non-D2 dissection

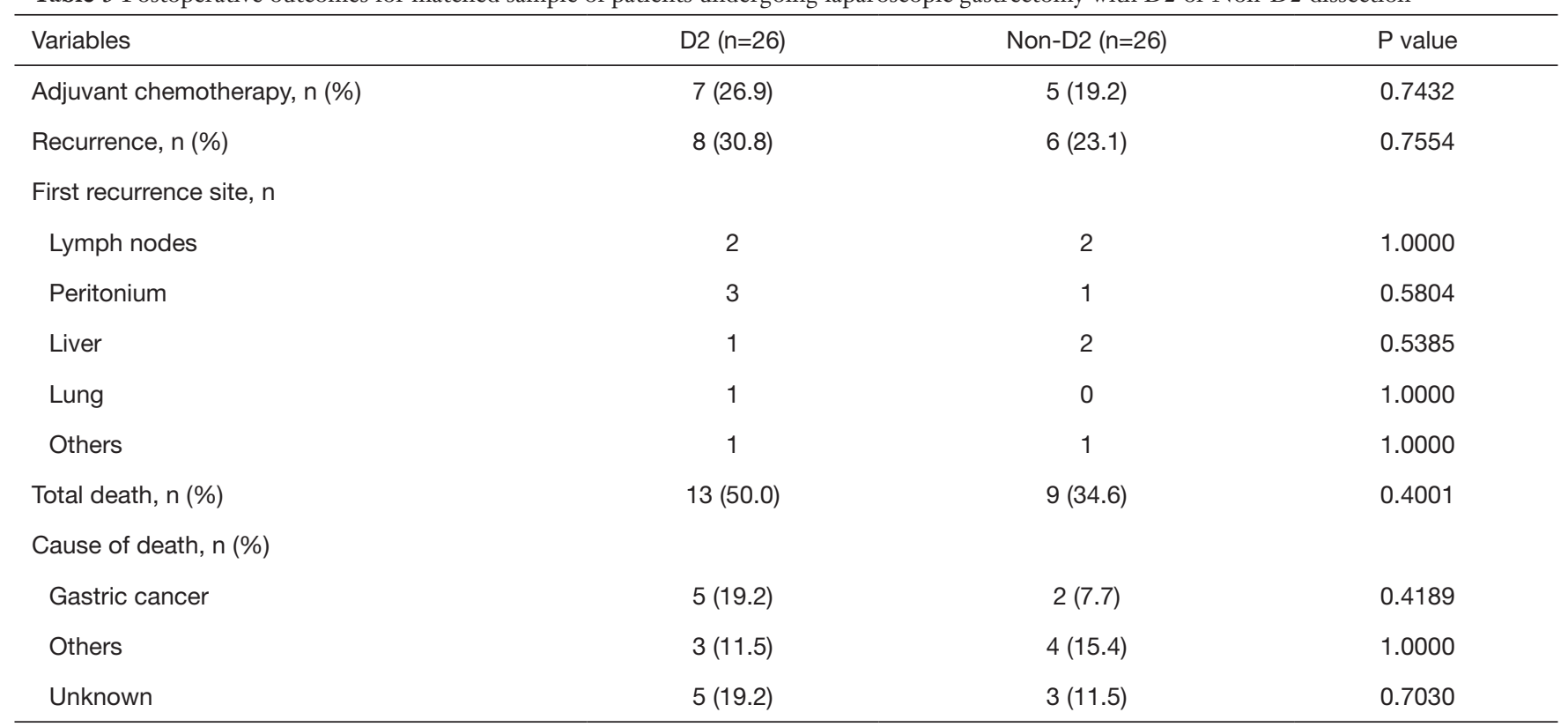

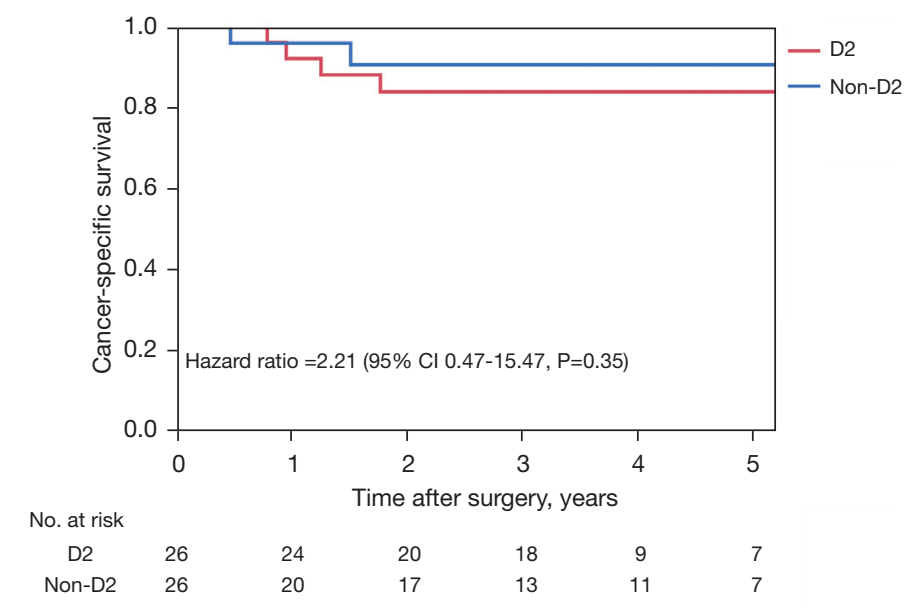

Figure 2 Cancer-specific survival.

be performed. Additionally, the absolute standardized differences of the two covariates were less than 0.10 , which meant that the covariates that were strongly associated with the outcomes were well-balanced. Therefore, we believe that this study had high comparability and reliable results and may contribute to the clinical question whether LG with the D2 dissection is oncologically beneficial for the elderly patients with GC.

This study showed that the D2 group had $11.5 \%$ of pancreatic fistula or intra-abdominal abscess, whereas none in the Non-D2 group did. One patient underwent LTG with splenectomy (LTGS). LTGS was reported to be associated with a high incidence of intra-abdominal infectious complications due to pancreatic ischemia or congestion, and mechanical damage to the pancreas (23). However, the others underwent LDG. We speculated that the intraoperative compression of the pancreas or thermal damage to the pancreas by an energy device for the extended lymphadenectomy might be partly responsible. In fact, the comparison of the two Korean randomized control 


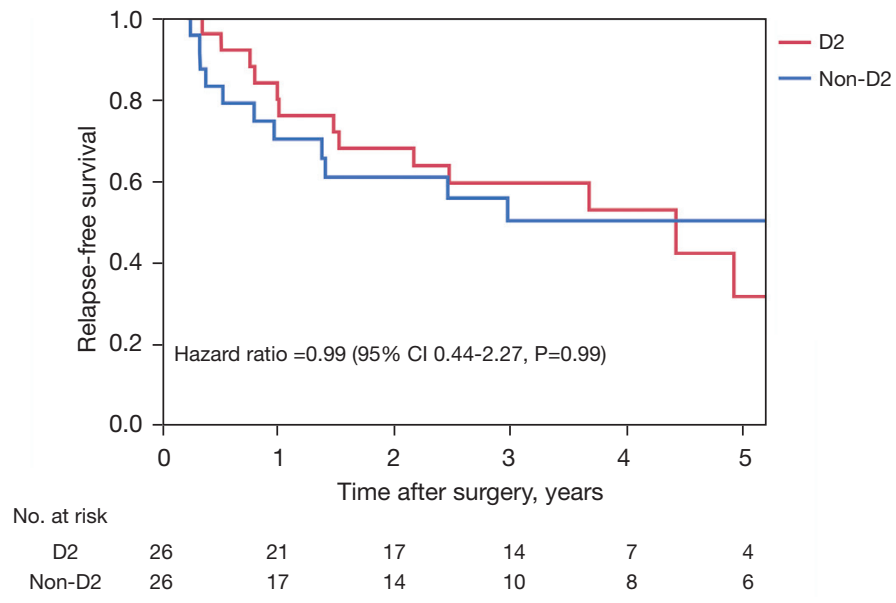

Figure 3 Relapse-free survival.

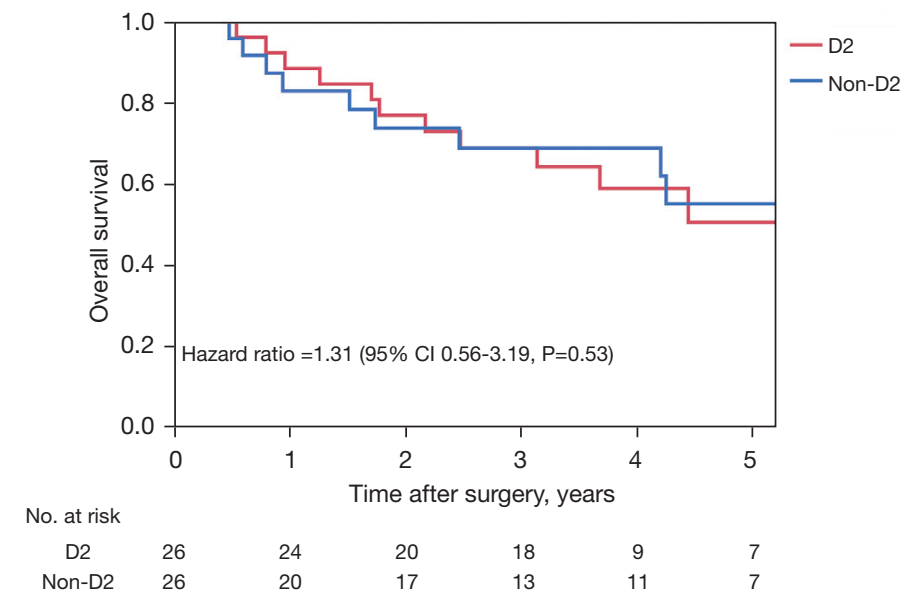

Figure 4 Overall survival.

trials (RCT), KLASS-01 for early GC, and KLASS-02 for advanced GC, showed that LDG with D2 dissection was associated with an increased occurrence of these complications compared to LDG with D1+ $(24,25)$.

The overall survival, which was the primary outcome of this study, was not significantly different between in the D2 and Non-D2 groups (3-year OS $68.8 \%$ vs. $68.8 \%$, Figure 4). Similarly, no significant differences were found in CSS and RFS. These outcomes were unexpected, because D2 LG could decrease the residual of the positive LNs and thus reduce the recurrence rate in theory. An Italian study comparing D1+ and D2 in GC using PSM showed that the lymph node harvest (LNH) favors D2 LG (26). However, there was no significant difference in the LNH in this study (D2 vs. Non-D2 = 44 vs. 38, $\mathrm{P}=0.1332)$. According to a 25,000 patient international database study, 29 LHNs were associated with an optimum survival benefit in patients with GC undergoing gastrectomy (27). The LNH in the Non-D2 LG in this study was much higher than 29. This result is a possible explanation for the lack of significant differences in the OS, CSS, and RFS.

A previous retrospective analysis comparing D2 with Non-D2 in a cohort of patients older than 80 years, using PSM showed similar results. Almost all the patients received OG. The rate of CD grade II or higher intra-abdominal abscess was significantly higher in the D2 group. The 3-year OS rate of the D2 group was lower than that of the Non-D2 group, although the difference was not significant. 
Therefore, they concluded that OG with D2 dissection for patients older than 80 years conferred little benefit despite an occurrence of increased complication rate (8).

This study had several limitations. First, this study was a single institutional retrospective study; therefore, it was subject to unobserved bias. Second, although PSM was able to achieve balance on the measured covariates, selection bias could not be eliminated. Notably, both groups were well-balanced in terms of patients' characteristics; however, pathological findings showed that the D2 group tended to have more advanced GC compared to the Non-D2 group. This might have influenced the long-term outcomes. Third, we did not evaluate the elderly patients based on a comprehensive geriatric assessment (CGA) and judged them as fit, vulnerable, and frail. CGA is an established method for evaluating the comorbidities, mental status, nutritional status, social circumstances, and polypharmacy, and may have a positive impact on the postoperative outcomes $(28,29)$. Some reports showed a significant relationship between frailty and postoperative morbidity (30). The major complication rates in this study were lower than those reported in the previous study (14). Considering these results, it is possible that we empirically selected highrisk patients who should undergo limited operations. It is important to develop a strategy for selecting high-risk patients who cannot tolerate D2 dissection.

\section{Conclusions}

This study showed that LG with D2 and Non-D2 were comparable in terms of oncological benefit; however, D2 LG tended to be associated with an increased occurrence of complications. These findings indicated that D2 LG could not be routinely recommended for elderly patients with GC.

\section{Acknowledgments}

We would like to thank Editage (www.editage.com) for English language editing.

Funding: None.

\section{Footnote}

Reporting Checklist: The authors have completed the STROBE reporting checklist. Available at https://jgo. amegroups.com/article/view/10.21037/jgo-21-640/rc

Data Sharing Statement: Available at https://jgo.amegroups. com/article/view/10.21037/jgo-21-640/dss

Peer Review File: Available at https://jgo.amegroups.com/ article/view/10.21037/jgo-21-640/prf

Conflicts of Interest: All authors have completed the ICMJE uniform disclosure form (available at https://jgo.amegroups. com/article/view/10.21037/jgo-21-640/coif). The authors have no conflicts of interest to declare.

Ethical Statement: The authors are accountable for all aspects of the work in ensuring that questions related to the accuracy of any part of the work are appropriately investigated and resolved. This study was conducted in accordance with the ethics of the Declaration of Helsinki (as revised in 2013). It was approved by the ethics committee of Japanese Red Cross Osaka Hospital (J-0238). The requirement to obtain individual patient consent was waived given the retrospective nature of study.

Open Access Statement: This is an Open Access article distributed in accordance with the Creative Commons Attribution-NonCommercial-NoDerivs 4.0 International License (CC BY-NC-ND 4.0), which permits the noncommercial replication and distribution of the article with the strict proviso that no changes or edits are made and the original work is properly cited (including links to both the formal publication through the relevant DOI and the license). See: https://creativecommons.org/licenses/by-nc-nd/4.0/.

\section{References}

1. Bray F, Ferlay J, Soerjomataram I, et al. Global cancer statistics 2018: GLOBOCAN estimates of incidence and mortality worldwide for 36 cancers in 185 countries. CA Cancer J Clin 2018;68:394-424.

2. Ministry of Health, Labour and Welfare. Vital statistics Japan 2019. Available online: https://www.mhlw.go.jp/ english/index.html

3. Allemani C, Matsuda T, Di Carlo V, et al. Global surveillance of trends in cancer survival 2000-14 (CONCORD-3): analysis of individual records for 37513025 patients diagnosed with one of 18 cancers from 322 population-based registries in 71 countries. Lancet 2018;391:1023-75.

4. Japanese Gastric Cancer Association. Japanese gastric cancer treatment guidelines 2018 (5th edition). Gastric Cancer 2021;24:1-21. 
5. Chen J, Chen J, Xu Y, et al. Impact of Age on the Prognosis of Operable Gastric Cancer Patients: An Analysis Based on SEER Database. Medicine (Baltimore) 2016;95:e3944.

6. Mengardo V, Cormack OM, Weindelmayer J, et al. Multicenter Study of Presentation, Management, and Postoperative and Long-Term Outcomes of Septegenerians and Octogenerians Undergoing Gastrectomy for Gastric Cancer. Ann Surg Oncol 2018;25:2374-82.

7. Endo S, Shimizu Y, Ikenaga M, et al. Survival benefit of gastrectomy for gastric cancer in patients $\geq 85$ years old: A retrospective propensity score-matched analysis. Surgery 2017;161:984-94.

8. Shinozuka T, Kanda M, Ito S, et al. D2 lymph node dissection confers little benefit on the overall survival of older patients with resectable gastric cancer: a propensity score-matching analysis of a multi-institutional dataset. Surg Today 2020;50:1434-42.

9. Katai H, Sasako M, Fukuda H, et al. Safety and feasibility of laparoscopy-assisted distal gastrectomy with suprapancreatic nodal dissection for clinical stage I gastric cancer: a multicenter phase II trial (JCOG 0703). Gastric Cancer 2010;13:238-44.

10. Kim HH, Han SU, Kim MC, et al. Effect of Laparoscopic Distal Gastrectomy vs Open Distal Gastrectomy on Long-term Survival Among Patients With Stage I Gastric Cancer. JAMA Oncol 2019;5:506-13.

11. Shinohara T, Satoh S, Kanaya S, et al. Laparoscopic versus open D2 gastrectomy for advanced gastric cancer: a retrospective cohort study. Surg Endosc 2013;27:286-94.

12. Choi YY, Bae JM, An JY, et al. Laparoscopic gastrectomy for advanced gastric cancer: Are the long-term results comparable with conventional open gastrectomy? A systematic review and meta-analysis. J Surg Oncol 2013;108:550-6.

13. Hu Y, Huang C, Sun Y, et al. Morbidity and Mortality of Laparoscopic Versus Open D2 Distal Gastrectomy for Advanced Gastric Cancer: A Randomized Controlled Trial. J Clin Oncol 2016;34:1350-7.

14. Kinoshita T, Uyama I, Terashima M, et al. Longterm Outcomes of Laparoscopic Versus Open Surgery for Clinical Stage II/III Gastric Cancer. Ann Surg 2019;269:887-94.

15. Yu J, Huang C, Sun Y, et al. Effect of Laparoscopic vs Open Distal Gastrectomy on 3-Year Disease-Free Survival in Patients With Locally Advanced Gastric Cancer: The CLASS-01 Randomized Clinical Trial. JAMA 2019;321:1983-92.
16. Hyung WJ, Yang HK, Park YK, et al. Long-Term Outcomes of Laparoscopic Distal Gastrectomy for Locally Advanced Gastric Cancer: The KLASS-02-RCT Randomized Clinical Trial. J Clin Oncol 2020;38:3304-13.

17. Katai H, Mizusawa J, Katayama H, et al. Survival outcomes after laparoscopy-assisted distal gastrectomy versus open distal gastrectomy with nodal dissection for clinical stage IA or IB gastric cancer (JCOG0912): a multicentre, noninferiority, phase 3 randomised controlled trial. Lancet Gastroenterol Hepatol 2020;5:142-51.

18. Japanese Gastric Cancer Association. Japanese classification of gastric carcinoma: 3rd English edition. Gastric Cancer 2011;14:101-12.

19. Bassi C, Dervenis C, Butturini G, et al. Postoperative pancreatic fistula: an international study group (ISGPF) definition. Surgery 2005;138:8-13.

20. Rubin DB. Using Propensity Scores to Help Design Observational Studies: Application to the Tobacco Litigation. Health Services \& Outcomes Research Methodology 2001;2:169-88.

21. Harder VS, Stuart EA, Anthony JC. Propensity score techniques and the assessment of measured covariate balance to test causal associations in psychological research. Psychol Methods 2010;15:234-49.

22. Stuart EA, Lee BK, Leacy FP. Prognostic score-based balance measures can be a useful diagnostic for propensity score methods in comparative effectiveness research. J Clin Epidemiol 2013;66:S84-S90.e1.

23. Kinoshita T, Okayama T. Is splenic hilar lymph node dissection necessary for proximal gastric cancer surgery? Ann Gastroenterol Surg 2021;5:173-82.

24. Kim W, Kim HH, Han SU, et al. Decreased Morbidity of Laparoscopic Distal Gastrectomy Compared With Open Distal Gastrectomy for Stage I Gastric Cancer: Short-term Outcomes From a Multicenter Randomized Controlled Trial (KLASS-01). Ann Surg 2016;263:28-35.

25. Lee HJ, Hyung WJ, Yang HK, et al. Short-term Outcomes of a Multicenter Randomized Controlled Trial Comparing Laparoscopic Distal Gastrectomy With D2 Lymphadenectomy to Open Distal Gastrectomy for Locally Advanced Gastric Cancer (KLASS-02-RCT). Ann Surg 2019;270:983-91.

26. Lorenzon L, Giudicissi R, Scatizzi M, et al. D1-plus vs D2 nodal dissection in gastric cancer: a propensity score matched comparison and review of published literature. BMC Surg 2020;20:126.

27. Woo Y, Goldner B, Ituarte P, et al. Lymphadenectomy with Optimum of 29 Lymph Nodes Retrieved Associated 
with Improved Survival in Advanced Gastric Cancer: A 25,000-Patient International Database Study. J Am Coll Surg 2017;224:546-55.

28. Reuben DB. Geriatric assessment in oncology. Cancer 1997;80:1311-6.

29. Partridge JS, Harari D, Martin FC, et al. The impact of pre-operative comprehensive geriatric assessment on postoperative outcomes in older patients undergoing scheduled surgery: a systematic review. Anaesthesia 2014;69 Suppl 1:8-16.

30. Tegels JJ, de Maat MF, Hulsewé KW, et al. Value of geriatric frailty and nutritional status assessment in predicting postoperative mortality in gastric cancer surgery. J Gastrointest Surg 2014;18:439-45; discussion 445-6.
Cite this article as: Sakaguchi M, Hosogi H, Kanaya S. Is D2 laparoscopic gastrectomy essential for elderly patients with advanced gastric cancer? A propensity score matched analysis. J Gastrointest Oncol 2022;13(1):67-76. doi: 10.21037/jgo-21-640 